\title{
Parents' acceptance and regret about end of life care for children who died due to malignancy
}

\author{
Kunal Das ${ }^{1}$ (D) Tanvi Khanna $^{1} \cdot$ Anshika Arora $^{2} \cdot$ Nitika Agrawal $^{1}$ \\ Received: 11 December 2018 / Accepted: 7 April 2019 / Published online: 1 May 2019 \\ (C) Springer-Verlag GmbH Germany, part of Springer Nature 2019
}

\begin{abstract}
Purpose To analyse the preference of end of life care place in paediatric oncology patients, and to understand the end of life care needs and regrets among the care givers.

Method This was an observational qualitative study. Parents of in-curable paediatric malignancy patients who died during the years 2016-2018 were interviewed using a pre-formed open-ended questionnaire. Fears during the last phase of child's life, most disturbing symptoms, choice of end of life care plan, regret of care givers and reasons for such choices were noted and analysed. Result Twenty six families were interviewed. A median of 3 months of discordance was noted between declaration of incurability and acceptance of the same by the family. During terminal months, pain (84.62\%) was described as the most bothersome symptom followed by respiratory distress (73.08\%). Eighteen families (69\%) opted for home-based terminal care, 8 (31\%) for hospital-based terminal care. Regret of choice was noted in $62.5 \%$ families of the hospital-based care group (separation from home environment being the main reason) and 38.89\% of the home-based care group (lack of access to health care personnel and pain medication being the main reasons).

Conclusion Home-based care is the preferred option for end of life care by the care givers. Lack of community-based terminal care support system and availability of analgesics are the main areas to work on in India.
\end{abstract}

Keywords End of life care $\cdot$ Palliative $\cdot$ Paediatric cancer $\cdot$ Terminal care $\cdot$ Qualitative study $\cdot$ Home-based palliative care $\cdot$ Cancer distress

\section{Introduction}

Death of a paediatric malignancy patient is not just a physical but also a huge psycho-social loss for the family. Decisions regarding the expected death of a child, like end of life care plan, hospital- or home-based care, are often taken into isolation by

Kunal Das

drkunaloncology@gmail.com

Tanvi Khanna

tanvikhanna@srhu.edu.in

Anshika Arora

anshikaarora@srhu.edu.in

Nitika Agrawal

drnitika80@rediffmail.com

1 Department of Pediatrics, Himalayan Institute of Medical Sciences, Swami Rama Himalayan University, Dehradun, India

2 Division of Palliative Care, Cancer Research Institute, HimalayanInstitute of Medical Sciences, Dehradun, India care givers and are seldom discussed with the child [1]. Pattern of end of life palliation opted by family has a variable spectrum. A study from Germany noted that $40 \%$ of advanced cancer cases opted for chemotherapy-based palliation, but majority regretted it in hindsight. While $80 \%$ of families, who opted for home-based terminal care, were satisfied with their decision retrospectively, as many as one-third of the families are not open to discussing the end of life care (EOLC) plan in detail with the treating team [2]. Even when explained about in-curability, parental perception and hope are often unrealistic [3]. Study from India noted that parents welcomed detailed information regarding EOLC care plan and support of hospital care as well as social services for home-based care. Studies have elaborated the symptoms encountered by the dying child as loneliness, fear of death, irritability and dullness. Despite interventions, satisfactory control was seldom achieved $[4,5]$.

Data regarding impact of socio-economic background and literacy are sparse. The Paediatric Oncology Division of Cancer Research Institute, Dehradun, India, caters to the population from sub-Himalayan terrain and neighbouring states. Our enlistment is mainly lower or low-middle class population 
with poor social support. This centre is a teaching medical school run by a trust and it delivers low-cost treatments to all conditions. The pattern of choice of palliation is probably different in such population. Knowledge about preferences will guide us to tailor palliation plan accordingly. Thus, this study was conducted to analyse the choices opted for end of life care plan in paediatric oncology patients, and to understand the end of life care needs, regrets and understanding of prognosis of the child by the care givers.

\section{Method}

This study was conducted at the Paediatric Oncology Division, Cancer Research Institute, Dehradun, India. The study population included paediatric oncology patients labelled as relapsed/refractory who died during the time period January 2016 to January 2018. Families of deceased children were contacted telephonically and requested for an interview. A briefing about the purpose of interview was mentioned. One parent of the child was interviewed and decision to enrol mother or father was entirely of family. The interview constituted of six structured sections in a pre-formed questionnaire, created by experts in the field, using a separate feedback obtained from an open discussion with ten families who lost their children due to progressive terminal cancer and some articles from previously published studies [6]. Interviews were conducted either in person or telephonically.

Sections of interview were designed to incorporate various aspects of terminal care (Table 1).

\section{Table 1 Questionnaire}

1. Questions regarding suffering of the child during his/her terminal month

a. Most disturbing symptoms noticed during the terminal month.

b. Other symptoms of concern during the terminal months.

c. Availability of medical help for those symptoms.

d. Effectiveness of medical interventions for those symptoms.

e. Grading of suffering of child (0-5 scale).

2. Questions regarding fear among family during terminal month

a. Most bothering fear of parents during terminal month.

b. Most complained fear of child during terminal month.

3. Question regarding time lag (in months) between medical team informing about in-curability of child's disease and family's acceptance of this fact.

4. Questions regarding any alternative treatment (non-allopathic) tried during this period.

5. Questions regarding end of life care plan.

a. Choice of terminal care place.

b. Reasons for such choice in the words of the parent.

6. Questions regarding any retrospective regret for the family's choice for end of life care plan place

a. Any regret?

b. Reasons for the regret if yes.
This was an open-ended interview in the language (Hindi) of the family member. One of the two researchers (KD or TK) conducted the interview. Families were given choice to express views beyond the specified questions, if they felt like. Guidance was available to the participant parent to understand the questions as and when required. Whenever an elaborate answer was given, parent was requested to summarise in points and answer was noted and discussed with them for final approval. Patients' hospital records were surveyed to record the timing of declaration of in-curability by the treating team, options of EOLC discussion, treatment options offered and consent for opting or declining intensive care in such a situation. Demographic profile of the patients and family, disease details, treatment received and family structure were noted as well.

This study was duly approved by institutional ethical committee (HIMS/RC/2018/199) and written informed consent was taken from each participant before enrolment in the study.

\section{Analysis}

The data was entered in Excel sheet and analysed using SPSS software. Two-tailed Fisher exact test was used for dichotomised data while chi-square and Student's $t$ test was used for individual variables. $P$ value of $<0.05$ was considered significant.

\section{Result}

A total of 234 paediatric patients were enrolled for oncological treatment during this time period. Figure 1 shows details of enrolment and final number included in the analysis according to the CONSORT guidelines. Out of 26 families, 9 came for face to face interview while 17 opted for telephonic interview. Average time spent for interview was $48 \mathrm{~min}$ when done telephonically and 75 min when done in person. All parameters were answered by all families. No one opted out to leave interview in between. The mother was the responder in $31 \%$ while father was the lead responder in others. Median age of parents interviewed was 36 years. All parameters were answered by all families. No one opted out to leave interview in between.

\section{The demographic and disease details of the study group}

The mean age of children was 12.04 years (range $=4-18, \pm$ 4.61 SD). The number of months lapsed between the demise of child and the interview was noted, the mean time from death was 17.88 months (range $=15-22, \pm 1.53 \mathrm{SD}$ ). The demographic details and disease parameters of deceased children are detailed in Table 2. The mean income of the families was Rs 18,080 per month (range $=8000-36,000, \pm 7330.98$ SD). 


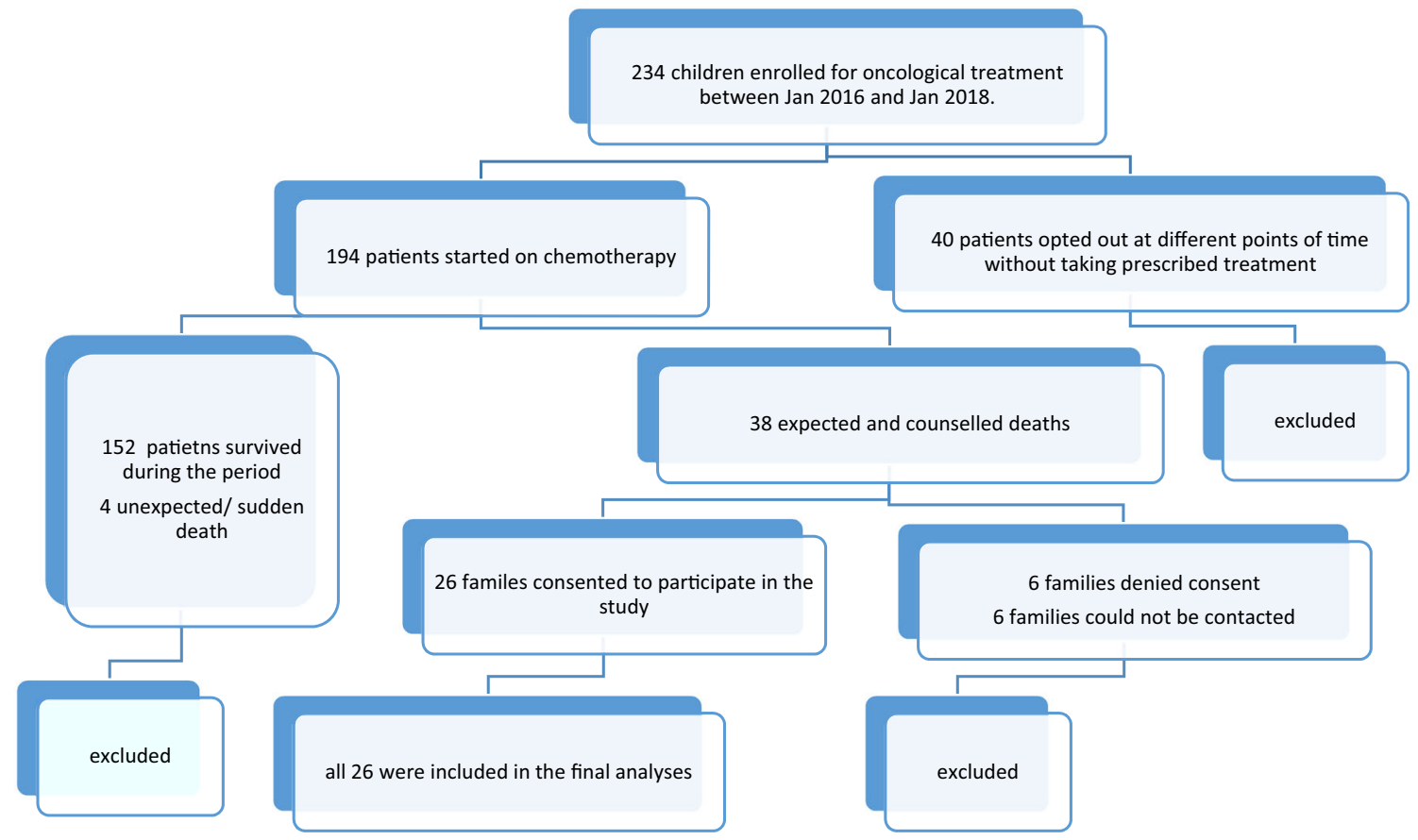

Fig. 1 The CONSORT guidelines diagram to show the enrolment and cases selected for final analysis in the study

\section{The terminal month of the child}

The median lag time between the declaration of in-curability and family's acceptance of the same was 3 months. After

Table 2 The baseline data of the patients and families $(N=26)$

\begin{tabular}{|c|c|c|c|}
\hline Variable & & Number & Percentage \\
\hline \multirow[t]{2}{*}{ Gender } & Male & 16 & 61.5 \\
\hline & Female & 10 & 38.5 \\
\hline \multirow[t]{2}{*}{ Residence } & Rural & 15 & 57.7 \\
\hline & Urban & 11 & 42.3 \\
\hline \multirow[t]{2}{*}{ Diagnosis } & Haematological & 15 & 57.7 \\
\hline & Solid & 11 & 42.3 \\
\hline \multirow[t]{2}{*}{ Sponsorship } & Self + partial sponsored & 10 & 38.5 \\
\hline & Fully sponsored & 16 & 61.5 \\
\hline \multirow[t]{3}{*}{ Treatment received } & Chemo & 19 & 73 \\
\hline & Chemo + RT & 6 & 23 \\
\hline & Chemo + surgery & 1 & 3.8 \\
\hline \multirow[t]{3}{*}{ Relapse } & Early & 23 & 88.5 \\
\hline & Metastatic & 2 & 7.7 \\
\hline & Progressive & 1 & 3.8 \\
\hline \multirow[t]{6}{*}{ Number of siblings } & 1 & 2 & 7.7 \\
\hline & 2 & 12 & 46.1 \\
\hline & 3 & 5 & 19.2 \\
\hline & 4 & 3 & 11.5 \\
\hline & 5 & 3 & 11.5 \\
\hline & 6 & 1 & 3.8 \\
\hline \multirow[t]{2}{*}{ Parent interviewed } & Father & 18 & 69.2 \\
\hline & Mother & 8 & 30.7 \\
\hline \multirow[t]{3}{*}{ Education of parent } & Illiterate & 9 & 34.6 \\
\hline & School & 14 & 53.8 \\
\hline & Graduate & 3 & 11.5 \\
\hline \multirow[t]{2}{*}{ Type of house } & Own & 16 & 61.5 \\
\hline & Rental & 10 & 38.5 \\
\hline
\end{tabular}

declaration of in-curability, $30 \%$ families opted for alternative chemotherapy while $20 \%$ opted for salvage regimen (chemotherapy for relapse/refractory cases) initially with belief of improvement and cure. However, only 3 patients were continuing these modalities even at the terminal week. The most disturbing symptom noted by the family during the terminal months of the children was pain followed by breathing difficulty (Table 3). Concerns about food intake and presence of altered sensorium were noted by almost every family. Median scale of severity of child's distress on 0 to 5 scale was 3 ; it was same for admitted and non-admitted patients.

\section{Choice of EOLC plan}

Only $30 \%$ families chose hospital-based terminal care for their child. The reasons for their choice were quoted as cost of care, distance from home, more children to attend at home, relative's pressure and fear of persistent symptoms (Table 4). None of the families consulted the child for his or her choice regarding the

Table 3 The most disturbing symptoms noted by the family during the terminal months of child $(N=26)$

\begin{tabular}{lc}
\hline $\begin{array}{l}\text { Most disturbing } \\
\text { symptom }\end{array}$ & $\begin{array}{l}\text { Number } \\
\text { (percentage) }\end{array}$ \\
\hline Pain & $14(54)$ \\
Respiratory & $8(30)$ \\
CNS & $2(7)$ \\
Bleed & $1(4)$ \\
Other & $1(4)$ \\
\hline
\end{tabular}


Table 4 The reasons quoted by the parent for choosing the place for end of life care plan

\begin{tabular}{lc}
\hline Reason & Number $(\%)$ \\
\hline Logistics & $10(38)$ \\
Relatives advices & $7(27)$ \\
Fear of terminal symptoms & $8(31)$ \\
\hline
\end{tabular}

place of EOLC plan. A total of $12(46 \%)$ families regretted their choice of EOLC plan in retrospect. This retrospective regret was more common with families opting hospital as EOLC place $(P=0.03)$ and also in families with selffinanced treatment $(P=0.179)$ (Tables 5). Pain was noted to be significantly more observed symptoms in the home-based EOLC group $(P=0.020)$ and respiratory distress was the most bothersome symptom among the admitted group (Table 6). Admitted children had easy access to medicinal remedies for their symptoms and $54 \%$ parent expressed their perception as near satisfactory for the control of symptoms temporarily. The hospital-based EOLC group regretted its decision with reasons - uncontrolled pain, fearfulness of child regarding the hospital environment and child's unfulfilled desire to be at home. The home-based EOLC group regretted its decision with reasons - uncontrolled pain and non-availability of medical help at home (Table 7). Only 3 patients that opted for home-based EOLC were visited by health care worker during terminal care. On univariate analysis using the Pearson chisquare test, only living in a rental house was significantly associated with the choice of home-based EOLC (Table 8).

\section{Discussion}

Paediatric oncology as a separate speciality was unrecognised for a long time in India. Surveys showed that majority of paediatric cancer patients were sub-optimally treated with either adult medical oncologist or self-trained paediatricians. Even separate beds or wards for paediatric oncology were not available in many medical colleges and hospitals [7, 8]. Resource allocation in such a large country has severe imbalance. While centres in metropolitan cities have specialised

Table 5 Cross-tabulation of place of EOLC plan and retrospective regret for the same $(P=0.033)$ (Fisher exact test)

\begin{tabular}{cllcr}
\hline & & \multicolumn{2}{l}{ Number of parents who regret (\%) } & Total \\
\cline { 2 - 3 } & \multicolumn{1}{c}{ Yes } & No & \\
\hline $\begin{array}{c}\text { EOLC place } \\
\text { opted }\end{array}$ & Home & $7(38.89)$ & $11(61.11)$ & 18 \\
& Hospital & $5(62.5)$ & $3(37.5)$ & 8 \\
\hline
\end{tabular}

Table 6 Cross-tabulation of end of life care plan chosen and the most disturbing symptom noted by the parent $(P=0.457$, Pearson chi-square test)

\begin{tabular}{clcc}
\hline & & \multicolumn{2}{c}{ EOLC place opted } \\
\cline { 3 - 4 } & & Home & Hospital \\
\hline \multirow{2}{*}{$\begin{array}{c}\text { Most disturbing } \\
\text { symptom }\end{array}$} & Respiratory & 4 & 4 \\
& Pain & 11 & 2 \\
& Altered sensorium/seizure & 1 & 1 \\
& Bleed & 1 & 1 \\
\multirow{2}{*}{ Total } & Other & 1 & 0 \\
\hline
\end{tabular}

paediatric oncology services and collaborative trials have started, rural India lacks the basic diagnostic facilities for such ailments and under reporting of cancers is common. Only $5 \%$ of the population has been covered by national registry in $2005[9,10]$. India has also witnessed a remarkable improvement in paediatric cancer survivorship and at dedicated centres; its rate is approaching comparable with western data.

With advancement in understanding of supportive care, paediatric cancers are curable in majority, yet long period of in-curable disease and eventual mortality is a fact faced by many patients. EOLC is needed in about 675,000 cancer cases and $25 \%$ of diagnosed paediatric cancer cases [11, 12]. Approach for care at time of impending death and beyond leads to the concept of end of life palliative care. By the 1980 s, this concept got attention in developed and developing world with people expecting a good quality of life even when death is anticipated [13-15]. India which hosts about one million of the cancer population is severely lacking in all aspects of palliative care and capacity building for it as well [16]. Paediatric palliative care need is different, as a child is not the decision-maker in majority of cases. His expression of symptoms and fear may not be adequately perceived or addressed by the care givers. With the passing of time, his preferences and expectation might change and a hospital-based care might be more dreadful for him. However, recent era

Table 7 The reasons for regret for the plan of end of life care plan chosen

\begin{tabular}{ll}
\hline Reason for regret & $\begin{array}{l}\text { Number (\%) } \\
\text { [out of 12 regrets] }\end{array}$ \\
\hline Absence of social support/family at terminal time & $5(41)$ \\
Doctor unavailable & $7(57)$ \\
Pain not attended & $8(65)$ \\
ICU separation regret & $1(8)$ \\
Child fear & $1(8)$ \\
\hline
\end{tabular}


Table 8 The end of life care place choice and demographic details

\begin{tabular}{llccc}
\hline \multirow{2}{*}{ Variable } & & \multicolumn{3}{c}{ EOLC place (Pearson chi-square test) } \\
\cline { 3 - 5 } & & Home & Hospital & $P$ value \\
\hline \multirow{2}{*}{ Gender } & Male & 12 & 4 & 1 \\
& Female & 6 & 4 & \\
Residence & Rural & 12 & 3 & 0.177 \\
& Urban & 6 & 5 & \\
Sponsorship & Self & 13 & 3 & 0.355 \\
\multirow{5}{*}{ Diagnosis } & Sponsored & 5 & 5 & \\
& Haematological & 10 & 5 & 1 \\
Relapse & Solid & 8 & 3 & \\
& Early & 17 & 6 & 0.49 \\
& Metastatic & 1 & 1 & \\
\multirow{2}{*}{ Type of house } & Own & 0 & 1 & \\
& Rental & 9 & 7 & 0.027 \\
& & 9 & 1 & \\
\hline
\end{tabular}

has witnessed concerns among medical fraternity for the need of paediatric palliative care guidelines.

The present study noted that about $16 \%$ patients needed palliative and end of life care. Hospital was opted as the EOLC place by $8 / 26$ while home was preferred by $18 / 26$ patients. Study at Cipla Palliative Care Institute noted that 83\% Indian cancer patients opt for home-based terminal care and the main reason was financial $[17,18]$. The study also noted majority of self-financed family opted for home-based palliation and they acknowledge financial constrains responsible for their choice.

In our study, child's distress and discomfort score, as perceived by parent, was of same grade in hospital- and home-based EOLC. However, temporary relief with medication was noted in a significant proportion of admitted patients, 3/7 participants still regretted the decision of opting hospital as terminal care site and majority were concerned with the restrictive atmosphere, non-segregation, lack of privacy and fear of death in child due to frequent medical and nursing interventions. The 2 families, who opted for ICU care and resuscitation, regretted it later as ventilation and sedation caused separation from their child at the terminal time. Regret was less among home-based EOLC-based parents and mainly limited to unavailability of medical aids for symptom relief. Intensive care supports for terminally ill oncological patients are not uniformly promoted. Lack of consensus among medical fraternity in India has been noted regarding ICU care, ventilator support, withdrawal and policy of no escalation of advanced life support treatment in such cases [19].

India has a diverse population and many religions. Social and religious believes play a major role in deciding terminal care. Each religion has defined good or desirable death as different. The common concept of Karma responsible for all sufferings and sufferings are purging for old sins are accepted by almost all religions. While extensive use of pain-alleviating medications is not accepted in Islam and Jainism, these decisions do changes with the paediatric population $[20,21]$. Social structure like combined family and availability of many relatives to visit during terminal days are common. A western model of opting hospice is not regularly cherished in Indian society. However, unavailability of community-based EOLC support and nonexistent home care assistance lead to regret by family [22].

Pain was noticed as the most disturbing symptom in this study and same was noted in the literature as well. Ease of getting morphine is other area of concern. In India, availability of morphine to a home-based terminal care patient is almost non-existent. Data regarding supply of morphine showed dismal figure [23, 24]. Community-based palliative care facility is also not available in majority of the states. Kerala, a state in India, established a model primary level palliative care with community participation. This was applauded by the WHO and World Palliative Care Alliance but unfortunately is not being followed by other states of the country [25]. Homebased palliation is often remembered as the terminal period without medical intervention by parents in this study [26].

This study noted interesting facts about choice of EOLC among paediatric cancer patients. However, the following limitations were noted. Firstly, this study was likely to harbour bias as families not opting to take the interview may be more disturbed and might have experienced more stressful terminal time. Secondly, the child's stress perception made by parents might not be accurate. Financial status emerged as a cause for opting home-based care; thus, social acceptance across all the economic strata could not be commented. Moreover, the small number of participants limits the conclusions to be generalised.

This study emphasises the need of palliative care facility at community level and availability of medical help at home level for dying children. A dedicated palliative team is desired to cope with the regret and distress noted by families after demise of children during the bereavement period.

\section{Compliance with ethical standards}

This study was duly approved by institutional ethical committee (HIMS/RC/2018/199) and written informed consent was taken from each participant before enrolment in the study.

Conflict of interest The authors declare that they have no conflicts of interest.

Abbreviations EOLC, end of life care; ICU, intensive care unit

\section{References}

1. Rosenberg AR, Orellana L, Ullrich C, Kang T, Geyer JR, Feudtner C, Dussel V, Wolfe J (2016) Quality of life in children with advanced cancer: a report from the PediQUEST Study. J Pain Symptom Manag 52:243-253 
2. Hechler T, Blankenburg M, Friedrichsdorf SJ et al (2008) Parents' perspective on symptoms, quality of life, characteristics of death and end-of-life decisions for children dying from cancer. Klin Padiatr 22:166-174

3. Kamihara J, Nyborn JA, Olcese ME, Nickerson T, Mack JW (2015) Parental hope for children with advanced cancer. Pediatrics 135 : 868-874

4. Beretta S, Polastri D, Clerici CA, Casanova M, Cefalo G, Ferrari A, Luksch R, Massimino M, Meazza C, Podda MG, Spreafico F, Terenziani M, Bellani FF (2010) End of life in children with cancer: experience at the pediatric oncology department of the Istituto Nazionale Tumori in Milan. Pediatr Blood Cancer 54:88-91

5. Theunissen JM, Hoogerbrugge PM, van Achterberg T et al (2007) Symptoms in the palliative phase of children with cancer. Pediatr Blood Cancer 49:160-165

6. Emanuei EJ, Fairclough DL, Daniels ER, Clarridge BR (1996) Euthanasia and physician- assisted suicide: attitude and experience of oncology patients, oncologists and the public. Lancet 347:18051810

7. Shenoy S, Christo GG, Venkatesh A (1990) Pediatric cancer care in India: a national survey. Indian J Cancer 27:91-96

8. Arora R, Arora B (2009) Delivering childhood cancer service across India: current provisions and future options. Pediatr Blood Cancer 53:827

9. Sarin R (2005) Indian National Cancer Control Programme: setting sight on shifting targets. J Cancer Res Ther 1:240-248

10. Swaminathan R, Sankaranarayanan R (2010) Under-diagnosis and under-ascertainment of cases may be the reasons for low childhood cancer incidence in rural India. Cancer Epidemiol 34:107-108

11. GBD 2015 Mortality and Causes of Death Collaborators: Global, regional, and national life expectancy, all-cause mortality, and cause-specific mortality for 249 causes of death, 1980-2015: a systematic analysis for the Global Burden of Disease Study 2015. Lancet 388:1459-1544, 2016

12. Landis SH, Murry T, Bolden S, Wingo PA (1999) Cancer statistics 1999. CA Cancer J Clin 49:8-31

13. Doyle D (1982) Domiciliary terminal care: demands on statutory services. The Journal of Royal College of General Practioner 32: 285-291

14. Allbrook D (1984) Dying of cancer-home, hospice or hospital. Med J Aust 141:143-144

15. Townsend J, Frank AO, Fermont D, Dyer S, Karran O, Walgrove A, Piper M (1990) Terminal cancer care and patients' preference for place of death: a prospective study. Br Med J 301:415-417
16. The Economist Intelligence Unit: The 2015 Quality of Death Index: Country profiles. https:/www.eiuperspectives.economist.com/ sites/default/files/images/2015\%20Quality\%20of\%20Death\% 20Index\%20Country\%20Profiles_Oct\%206\%20FINAL.pdf

17. Kulkarni P, Kulkarni P, Anavkar V, Ghooi R (2014) Preference of the place of death among Indian people. Indian J Palliat Care 20:611

18. Jayaram R, Ramakrishnan N (2008) Cost of intensive care in India. Indian Journal of Critical Care Medicine 12:55-61

19. Balakrishna S, Mani RK (2005) Constitutional and legal provisions in Indian law for limiting life support. Indian Journal of Critical Care Medicine 9:108-114

20. Firth S (2005) End-of-life: a Hindu view. Lancet 366:682-686

21. Bauer-Wu S, Barrett R, Yeager K (2007) Spiritual perspectives and practices at the end-of-life: a review of the major world religions and application to palliative care. Indian J Palliat Care 13:53-58

22. Sharma H, Jagdish V, Anusha P, Bharti S (2013) End-of-life care: Indian perspective. Indian J Psychiatry 55(Suppl 2):S293-S298

23. Pallium India: Morphine consumption in India. http://palliumindia. org/2014/02/morphineconsumption-in-india/

24. Foley KM, Wagner JL, Joranson DE et al (2003) Pain control for people with cancer and AIDS. In: Disease control priorities in developing countries. Oxford University Press, New York, pp 981994

25. World Palliative Care Alliance: Global atlas of palliative care at the end of life. http://www.who.int/nmh/Global_Atlas_of_Palliative Care.pdf

26. Cleary J, Silbermann M, Scholten W, Radbruch L, Torode J, Cherny NI (2013) Formulary availability and regulatory barriers to accessibility of opioids for cancer pain in the Middle East: a report from the Global Opioid Policy Initiative (GOPI). Ann Oncol 24:xi51-xi59, (suppl 11)

Publisher's note Springer Nature remains neutral with regard to jurisdictional claims in published maps and institutional affiliations.

Key note Home-based end of life care is preferred by parents of dying children although unavailability of health care support and pain medication at community level was the cause of regret among majority. 